\title{
O TURISMO E AS NORMAS ISO 9000 Um Caminho para a Certificação da Qualidade dos Produtos e Serviços ${ }^{1}$
}

\author{
Josć Roberto Yasoshima²
}

\begin{abstract}
RESUMO: Um novo cenário econômico mundial mostra que a qualidade dos

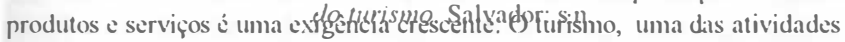
mais importantes di atualidade, deve levar as empresas do setor a adotar uma nova postura visando a qualidade a produtividade. A centificaçãode um sistema de qualidade total $\mathrm{e}$ o melhor caminho para o reconhecimento internacional.

PALAVRAS-CIIAVE: Turismo: qualidade de produtose serviços; marketingde serviços: qualidade total; certificação; IS() 9000.

ABSTRACT: A new world economic scenery shows the increasement of products and services quality' request. While one of the most important activity' tourism requires a new position of all turistic organizations in the way of quality and productivity. The total quality system certification is the best way for a world-wide recognition.
\end{abstract}

KEY WORDS: Tourism: products and services quality: services marketing: total quality, certification; ISO 9000.

\section{INTRODUÇÃO}

Os anos $9($ começaram com profundas modificações politicas, sociais e econômicas. A queda do muro de Berlim, em 9 de novembro de 1989, foi a imagem que melhor simbolizou todo o processo de transformações que iriam ocorrer na última década do sćculo XX.

I Trabalho apresentado origimalmente no "I Simpósio Latinoamericano de Docentes e Pesquisadores Cientificos en Turismo", Bahia, Brasil, em novembro de 1993.

2 Bacharel em Administração de Empresas e Especialista em Didática

Universidade Mackenzic. Lispecialista em Planificação Estratigica do Turismo pela Escola de Comunicaçõese Artes da USP. Mestrando em Turismo e Lazer na Escolade Comunicaçõese Artes da USP. End. para corresp.: Av. Angélica, 2389, apto. 42 A - Higienópolis - CEP’ $01227-906$ - São Paulo - Sl' - Brasil. 
Uma nova ordem econômica começou a ser delineada, bascada em três primcipais fatores:

a) a globalização da e conomia, trazendo cm scu rastro a abertura dos mercados para o livre comćrcio, dernubou antigos mitos ligados aos conceitos de hegemonia das grandes corporações. Muitas dessas empresas tinham na cconomia de escala o seu maior trunfo de domínio, expansão c conquista de mercado, mas a redução nos custos diretos da produção não se refletia mais $\mathrm{cm}$ scus balanços. Pelo contrário, os resultados começaram a cxibir prejuízos, decorrentes de cstnuturas cada vez mais onerosas acumuladas para dar sustentação ao crescimento. As empresas menores, mais leves c ágeis, adaptaram-se com maior facilidade às novas regras da economia que priorizavam a qualidade/produtividade, como a melhor arma para competir.

b) o fim da União Sovićtica não pode ser atribuido somentc a razões econômicas ou politicas. Como observa DRUCKER (1993), a principal razão é existencial. É tendência para o tribalismo que demonstra a necessidade que as pessoas têm de viver cm comunidade, cm fixar suas raizes, num mundocadì vez mais transnacional. A formação de blocos econômicos aparentementc surgiu como um paradoxo, mas as tendências mundiais, se de um lado apontavam para a independência política e o autogoverno, por outro revelavam uma procura de aglutinação para a formação de alianças cconômicas (NAISBITT, 1994);

c) os tradicionais sistcmas da produção industrial foram substituidos por uma economia com a maior parte de sua mão-de-obra alocada no setor cle serviços. Por volta do ano $2000($ todas as previsões indicam a relação em que apenas um sexto a um oitavo da força de trabalho estará envolvida diretamente com a produção industrial. A grande massa dos trabalhadores estará concentradil no setor de serviços. O desemprego, obsenado principalmente nos países mais desenvolvidos, tem causas estruturais muito mais relacionadas com 0 avanço tecnológico do que com a recessĩo.

A revolução lecnológica serve de pano de fundo para esse novo cenário econômico catinge todos os setores. O tradicional modclo do sistcma industrial foi profundamentc modificado pela automação c robotização.

Os avanços no campo das telecomunicações e informática redesenharaill o modelo de uma nova sociedade pós-industrial, caractcrizada pela importâncli: que é dada à informação e ao conhecimento, tratados como seus principalis insumos (DRUCKER, 1993)

\section{O TURISMO E A NOVA ORDEM ECONÔMICA MUNDIAL}

O sctor de turismo não só foi afctado, como também se tornou um dos maiores beneficiários das mudanças que estão ocorrendo. Tem a vantagem adicional de reunir maiores condições de adaptação às novas realidades. podendo acompanhar pari passin o ritmo veloz das transformações. Assim:

a) a globalização da economia vai ao encontro da cxpectativa do turista que vế cmsuas férias uma possibilidade de fugada consistência que lhe é garantida pela rotina do seu cotidiano (MILL \& MORRISON, 1992). A procura de destinos alternativos, incluindo cidades e países cxóticos com allo gran de complexidacle (lingua, cultura, culinária, costumes), ć balanceada por uma dose de consistênciaque a globalização permitc. Hoje o turista viaja com mais scgurança c certeza de poder se alojar num hotel de uma rede conhecida, de fazer suas refeições numa cadeia de fast food que the ć familiar. A abertura de mercados pressupõe maior intercâmbio entre os scus agentes, vendedores c consumidores. Permite, também, uma intcração cross cultural mais profunda entre os povos. O fim das grandes corporações pode representar o advento de uma nova era de oportunidades para um maior número de cmpresas de turismo de pequeno c médio porte. A competição por mercados scrá uma luta acirrada, travada muito mais no campo do diferencial da qualidacle clos produtos e serviços, agregado à imagem corporativa, do que no preço ou no porte das empresas;

b) a formação dos blocos econômicos funcionará como uma poderosa alavanca para o descnvolvimento do turismo inter-regional, como ocorre em larga cscala na Europa. A "eliminação" das barreiras geográficas c alfandegárias ćum incentivo aolivre trânsito càs viagens mais freqüentes, porém de menor duração. Muitos efeitos negativos da sazonalidade serão minimizados com um ajuste mais harmônico das curvas da demanda c da oferta, nas suas dimensões de tempo c espaço;

c) a expansãodo setor de senviçosć o ponto fulcral dessa nova ordem cconônica c, talvez, o fator que mais diz respeito ao turismo. O WTT\&C prevê que o setor será a atividade cconômica responsável pela criação do maior número de empregos nos próximos de\% anos. totaliðando cerca de 2() + milhões de empregos, ou 10,6\% da força de trabalho mundial para 1994, devendo atingir a cifra de $35($ ) milhões de empregos, aproximadamente $12 \%$ da força de trabalho, no ano de 2005 .

De acordo com dados do Banco Mundial c da Conferência das Nações Unidas sobre Comćrcio c Desenvolvimento (UNCTAD) de 1992, no ano passado o setor de serviçosmovimentou um trilhão de dólares - $22 \%$ de todo o 
comércio internacional Cerca de $60 \%$ do volume anual de investimentos externos estão ligados à indústria de serviços.

Os altos índices de desemprego registrados nos países industrializados estão mudando até o papel social e as relações capital e trabalho. Há quinze anos, alguns sindicatos europeus manifestavam o desejo de lutar pela semana de 35 horas, como forma de melhorar a qualidade de vida e diminuir o desemprego (SUE, 1988). Em 1992 foram as empresas que tomaram a iniciativa de propor não só a semana de 35 horas, como também o aumento do período de férias e a forma menos traumática de evitar demissões e de diminuir o desemprego 0 setor de turismo e lazer será responsável pela diminuição dos índices de desemprego, através de uma dinâmica que se pode chamar de "ciclo de emprego sustentado pelo lazer": a diminuição do número de horas trabalhadas e o aumento do tempo livre aumentarão a demanda maior pelas viagens de turismo e lazer. Esse crescimento da demanda exigirá novos investimentos na área de turismo e entretenimento para adequação da oferta no nível da demanda. E o aumento da oferta propiciará a geração de empregos na área da construção civil, infra-estrutura, transportes e serviços turísticos.

A revolução tecnológica tem alguns reflexos negativos $\mathrm{cm}$ algumas partes do setor de turismo. Muitas empresas do setor tinham no segmento das viagens de negócio uma preciosa fonte de recursos aparentemente inesgotáveis. As normas mais rígidas de contenção de despesas encontraram no avanço das telecomunicações e da informática os meios ideais para a racionalização. As redes internacionais de telecomunicações permitem hoje o trabalho de equipes multinacionais sem a necessidade do deslocamento de seus membros. A videoconferência e o fax são alguns exemplos de produtos responsáveis pela diminuição da ocupação de assentos na primeira classe e classe executiva de muitas acronaves, no baixo índice de ocupação de alguns hotéis. O progresso tecnológico está garantindo às empresas não só uma diminuição nos custos diretos das despesas de viagem (passagem, hospedagem, transportes), como também a redução dos custos indiretos, muito mais importantes e geralmente não computados, como o tempo de espera e deslocamento, o estresse associado ao dilema em que o empregado se vê na viagem de serviço, a sua responsabilidade funcional para com a empresa no cumprimento da missão em confronto com a sua responsabilidade social para com a sua família.

Mas, a médio e longo prazos os aspectos positivos do progresso tecnológico superarão os seus impactos negativos. Osetor de turismo poderá usar com maio intensidade as telecomunições e a informática no aprimoramento de suas estratégias de marketing na busca de novos segmentos e nichos de mercado, ${ }^{c}$ na melhoria da qualidade dos produtos e serviços prestados

\section{QUALIDADE, UM REQUISITO INDISPENSÁVEL PARA A COMPETITIVIDADE NO SETOR DE TURISMO}

Se tratada dentro do modismo que a reveste, a palavra qualidade poderia ser traduzida por dezenas de definições, cada uma mais criativa do que a outra, com recheios para todos os públicos e para todos os gostos.

Juran ébem sintético em sua definição. Para ele "qualidadeća adequação ao uso".

Na terminologia da ISO

qualidade é definida como a totalidade de caracteristicas de uma entidade que the confere a capacidade de satisfazer as necessidades explicitas e implicitas (ABNT, 1993).

As duas expressões "adequação ao uso" e "satisfação das necessidades explícitas e implícitas", extraídas das definições acima, acenam para uma mesma direção, a qualidade voltada para o cliente.

A qualidade, conjunto de características do produto ou do serviço, tem caráter objetivo, que é a condição de poder mensurar essas características ou, na falta de medidas, a possibilidade de compará-las com aquelas de um modelo.

A finalidade dessas características é a satisfação das necessidades dos consumidores. A necessidade pode ser expressa quando o consumidor solicita um produto ou serviço sob medida, ou pode ser implicita ou potencial, cabendo à empresa a tarefa de detectá-la através de pesquisas de mercado.

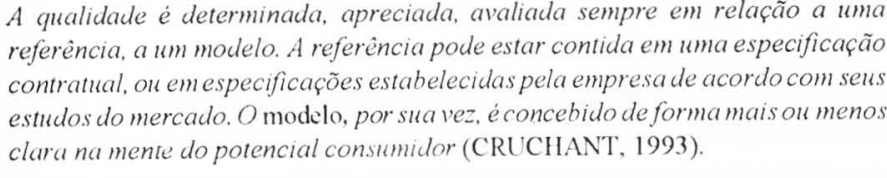

A qualidade é determinada, apreciada, avaliada sempre em relação a uma referência a um modelo. A referência pode estar contida em uma especificação contratual ou em especificacões estabelecidas pela empresade acordo com seus

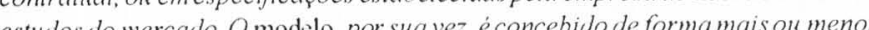
. clara na mente do potencial constumidor (CRUCHANT, 1993).

A qualidade não significa a melhor performance, mas sim a performance especificada para responder a uma determinada necessidade. Assim, não tem sentido comparar a qualidade de um restaurante fast food com a de um restaurante de "alta classe", a de um hotel de "duas estrelas" com a de um outro de "cinco estrelas". Pois somente pode-se comparar produtos e serviços dentro de uma mesma escala. Nesses casos categoria ou classe não são sinônimos de qualidade.

O consumidor dos anos 90 é caracterizado por um alto grau de exigência no que concerne à qualidade dos produtos e serviços que adquire. Esse aumento no nivel de exigência é fruto do fluxo maior e mais veloz das informações, da diversificação nas opções de escolha e na crescente conscientização do conceito da ética, pressuposto norteador das relações sociais em geral. 
Um problema que ocorre com um turista pode estar sendo transmitido quase que simultancamente para todo o mundo. ocupando a midia durante tempo suficiente para informare formar opiniāo de outros potenciais viajantes

O mercado. ao cxibir o leque de opções de at ratividades. permitc ao turis a escolha dos produtos e serviços que mais se ajustem à sua percepçĩo de garantia da saltisfaçĩo de suas necessidades.

Finalmente a cxigência de maior ćtica nas relações politicas. econômicas c sociais é um movimento de conscientizaçĩo que. também. se estende ao consumidor turista. Essa conscientizaç̧ĩo colctiva gerou um novo consumidor chamado por Dorothy Philips (ALBRETCH \& BRADFORD. 1992) de take charger (o cobrador de dircitos), muito concentrado cm si mesmo.

Os consumidores têm conseguido forçar a claboração de leis c códigos de proteçĩo que os põem ao abrigo das violações de seus dircitos. Num merâdo global. Cada vez mais competitivo, uma açĩo isolada de um cliente pode comprometer seriamente a imagem corporativa atć das maiores organizações.

No final de 1989) a Pan Am, cm anúncio de página intcira publicado cm jornais americanos. assumia ter cometido um erro básico $\mathrm{cm}$ sua polític mercadológica: envolvida em assuntoscorporativos, simplesmente esquecera os seus clientes nos últimos anos. Foi o então presidente da cmpresa. Thomas Plaskelı, quem assinavà a confissão pública (SZWARC. 199())

O anúncio foi inócuo e não conseguiu sallvar a sevagenária companhia da falência. Seus crecutivos sistematicamente vinham desprezando os escores que as revistas especializaldas publicavam mensalmente sobre os principais indicadores de desempenho das companhias aćreas, como problemas de cancelamento c atrasos devôos, falhas mecianicas, perdas c danosde bagagens, mau atendimen10, má qualidade dos serviços de terra c de bordo. Em agosto de 1987, a Pan Anl ocupava a quinta posição entre as dez maiores companhias aćreas ameriçallas cm relação ao número de queivas por passigeiros transportados. No mês seguinte subia para a quarta posição no total de queivas e para a primeira. noiten referente a atraso nos vôos (ROSANDER, 1989).

A história da falência da Pan Am é a comprovação de que não eviste imunidade c nem cura, quando a doença diagnosticada revela um comportamento crônico de maus serviços prestados e desprezo pelos clientes.

Além das erentuais reparações a que estĩo sujeitas, por não cumprirem als disposições contratuais, o risco maior a que estão cxpostas as cmpresas ć o da propaganda negativa. cm geral feila boca a boca. fatal para a sobrevir ĉncia num setor tão sensivel ao principio da gencralização. como ć o turismo.

A Pan Am que não conseguiu sobreviver nessa década da qualidade demonstrou que a má qualidade na prestaçīo de serviços não ć coisal de pais subdesenvohvido. Basta folhearalgumas rev islasespecializaldas em turismo piril se constatar que se trata de um problema universal. A americana ('ondé. last
Traveler tcm una seçĩo. chamada "Ombudsmann". cm que são registradas as queisas mais graves relatadas por turistas. A italiana Tuttoturismo. abre sua coluna "Il Muro del Pianto" (O muro da lamentaçiōo) para todos os turistas que se sentem lesados em seus dircitos. Mesmo com o dircito de defesal dado is empresas acusadas. pode-se verificar que os problemas de maus serviços sĩo comuns $\mathrm{c}$ gencralizados em todos os quadrantes do planetia

\section{AS NORMAS ISO 9000, UM CAMINHO QUE PODE SER SEGUIDO PELO TURISMO}

A natureza peculiar dos produtos e serviços turisticos, o caráter multifacelado das atividades $c$ as suas caracteristicas diferenciais intrin secas e extrinsecas dificultam a claboração de padrões, de normas e de legislação que possam disciplinar. altarés de paradigmas. a condula das partes envolvidas: turistas, agentesde viagens, hoteleiros, transportadores, restaurantes $\mathrm{ctc}$

A norma de qualidade ć o valor de referência para a ação cconômica da empresa de turismo. Ela deve fazer parte de um conjunto de regras, de um sistema de valores que a empresa ou a organização postula para poder se conduzir ou Se orientar quando sĩo aprescntados vários caminhos (OMT. 1988)

Em 1985, a Assemblèia Geral da Organizaçĩo Mundial de Turismo, reunida cm Sófia (Bulgária), promulgou a Tourism Bill of Righls and T'ouris Code (Carla do Turismo c o Código de Dircitos do Turista - OMT, 1985). concitando todos os Estados membros a aplicarem os principios maiores. expresso nesse documento, através de legislaçĩo e regulamentação respectival Nos artigos VIII e IX do documento promulgado sĩo feitas menções claras à qualidade dos produtos $\mathrm{e}$ dos serviços. Entretanto percebe-se a dificuldade $\mathrm{em}$ se traçar padrões universais para avaliaçĩo e o reconhecimento da qualidade na area dos serviços. Atć hoje as tentativas feitas nesse sentido se restringiram a classificação de hotéis e restaurantes. feitas pororganismos nacionais de turismo ouassociações particulares. Embora algumas classificações sejam reconhecidamente claboradas de forma critcriosa e séria. como é o caso do (iuria M/ichelin, na França, c do (iura (uratro Rodas, no Brasil. sĩo trabalhos que se prenden mais aos aspectos tangiveis e. portanto, mais facilmente mensuráveis. turismo?

Por (que a ulilização das nommas ISO) 9000 seriam mais adeecpuadas ao

Existem vários organismos internacionais especializados cm desenv olvimento de normas de qualidade para aplicações indusıriais especificas. Com a global ǐaçĩo daeconomia nasceua necessidade de seterum conjunto harmônico 
de normas genéricas sobre garantia da qualidade aplicáveis a todas as linhas industriais e de reconhecimento internacional. Esse vazio foi preenchido pela International Organization for Standardization - ISO (PURI. 1994)

Fazem parte da ISO organismos de normalização de mais de ()() países A participação do Brasil ć feita através da Associação Brasileira de Normas Técnicas (ABNT)

As normas ISO ()()() foram introduzidas no Brasil em 19y() c a mobilização das empresas para a adequação de seus sistemas de qualidade vem crescendo todo ano. Em novembro de 1992. o Brasil contava com 38 cmpresas certificadas; cm março de 1993. o número foi elevado para 8(). fechando o ano com mais de $18($ ) cmpresis. Os dados mais recentes indicavam que. no final de março de 1994. já existiam 285 companhias certificadas. É bom lembrar que na Itália cexistem cerca de $3(0)$ empresas certificadas, na Argentina apenas 3.

Preocupada com a importância que o setor de serviço associaclo ao produto adquiriu. demonstrada pelo maior poder de in fluĉncia do consumidor no final do processo de produção, a ISO resolveu ampliar suas normas para o setor de senviços em geral. Em 1991 foi lançada a norma internacional ISO 9()(4-2: "Gestão de Qualidade c Elementos de Sistemas da Qualidade - Parte 2: Diretrizes para Senviços", seguindo os mesmos princípios básicos que orientaram a claboração das normas anteriores. De acordo com a própria ISO, a norma ISO ()()4-2 ć uma resposta à necessidade cada vě maior de conhecimento de sistemas de qualidade, para o encorajamento das organizações a administrarem os scus processos de forma efetiva.

Como exemplos de atividades em que a norma ISO 9()()4-2 pode ser aplicada, no seu anexo A (informativo) encontram-se al guns setores de senviços, dentre os quais citam-se os que mais se relacionam com o turismo:

a) serviços de hospitalidade:

b) "catcring":

c) turismo cm geral:

d) entretenimento

e) lazer:

I) comunicações:

g) acroportos c linhas aćreas,

h) rodovias:

i) ferrovias:

j) transporte marítimo

Por terem sido adotadas inicialmente por cmpresas industriais. muitos profissionais da área de turismo podem entender que só empresals de grande porte têm acesso aos cobiçados certificados da séric ISO $)(())$. Mas a propria norma define a sua abrangência:
Os concellos e principios desta parte da ISO $1010+$ são adequados tanto para grandes como para pequenas empresas. Gimhora as pecuenus empress nĩo mesmos principios são aplicaveis. A diferença é simplesmente na escala (ISO $9(004-2.1991)$

\section{CONCLUSÃO}

Com a unificação curopéia c o crescimento do turismo inter-regional, a Comissão Européia tem diante de si o desafio de iniciar uma investigação que possa delinear os caminhos para o melhoramento das informações sobre a qualidade dos serviços turísticos dos paises membros, relata o jornalista Nick TRENDS (1994), do The European. A tarefa da Comissĩo deve contemplar amplo espectro de opiniões, tanto dos consumidores como dos agentes di indústria turística. Os membros da Comissão deverão estar bem-equipados para encontrar respostas - mas, dada à caótica situação da classificação dos hotćis entre os vários paises europeus, trata-se de uma missão

Sendo mais otimistas do que o jornalista curopeu: a qualidade, o grande leitmotiv desta última década do século XX. faz parte da própria essência dos serviços, e sua aplicação ao setor de turismo ć condição fundamental para a própria sobrevivência dos seus produtos e serviços

Os pioneiros nas pesquisas naárea de marketing de senviços, ZEITHAML PARASURAMAN c BERRY (199) ) são enfáticos cmafirmarque a qualidade nos serviços não pode ser uma idćia amorfa ou mística. O serviços para cles, podem ser definidos,

Com o enraizamento do conceito de qualidade total, a tendência prevista para o turismo ć de que em breve o consumidor turista, ao planejar sua viagem. procurará uma agência certificada. fará seu deslocamento através de uma empresa de transportecertificada, alojarr-se-á cm um hotel certificado, fará suas refeições $\mathrm{cm}$ restaurantes certificados e visitará atrações certificadas. Algumas empresas hoteleiras (grandes redes, villages) jái cstão adotando processos integrativos sinalizando claramente essa tendência para a qualidade total. Na seqüência de senviços que compõem uma viagem ou um pacote turístico, qualquer elo mais fraco da corrente poderá decretar a nuptura de todo o conjunto

No turismo o grau de complexidade nas relações contratuais ć maior cm vista da natureza peculiar do

produto turistico. um produto composto, um amálgama formado por varios componentes: operadoras e agencias de viagens. transportadoras, serviços receptivos locais. hotéis, entretenimentos (Li)(il. 1990). 
Os problemas de qualidade ocorrem justamente nas várias interfaces dos agentes do sistema.Uma das grandes vantagens da certificação é justamentc aumento da confiabilidade nas relações contratuais.

As interações humanas são ponto crucial da qualidade do serviço, própria ISO reconhece. Procurando estar na vanguarda, a organização esta revisando todas as normas da séric ISO 9000, devendo editar $\mathrm{cm}$ breve um atualização com importantes mudanças no seu conteúdo. Deverão ser incorporados itens relacionados com o programa de treinamento de funcionários enfatizando a qualidade de vida dos envolvidos $\mathrm{c}$ o meio ambiente.

A opção por uma empresa que tenha um certificado ISO não dá a certc\% de que não ocorram falhas, mas o turista terá a garantia de estar lidando com uma organização administrada dentro de um sistema dequalidade total. Em ciso de falha, certamente o problema será rapidamente detectado e resolvido

Essa busca pelo "passaporte" de qualidade deverá ter um crescimento no setor de serviços, da mesma forma como ocorre hoje no setor industrial e seri a grande vantagem competitiva das empresas certificadas tanto para a conquisti de novos mercados, como para a manutenção de um posicionamento positivo

A obtenção de um certificado é um processo longo e tem um custo do implementação, sendo imprescindivel a participação de todos dentro de uma organização.

Para que os programas de implantação de sistemas de qualidade tenhan êxito, uma nova postura vai tornando-se essencial: a parceria entre o sctor acadêmico e as empresas do setor de turismo.

A universidade $\mathrm{c}$ as escolas de turismo estudando e pesquisando os processos de prestação de serviços, e sempre respeitando as características das empresas, dos vários setores. Estes, por sua vez, reconhecendo que a qualidade não se conquista mais com improvisações e mão-de-obra desqualificada. A união, neste caso, faz a força c a qualidade.

\section{REFERÊNCIAS BIBLIOGRÁFICAS}

ABNT. ASSOCIAÇÃO BRASILEIRA DE NORMAS TÉCNICAS. 1993. Gestão da qualidad e garantia da qualidade. Terminologia; NBR ISO 8402. Rio de Janeiro: ABNT.

ALBRECHT Karl \& BRADFORD Lawrence J. 1992. Serviços com qualidade: a vantigè competitiva. São Paulo 2 ed.: Makron Books.

CRUCHANT, Lucien. 1993. La qualité. Paris: Presses Universitaires de France.

DRUCKER Petr F 1993. Post-capitalist socity. New York: Harper Busins.

ISO. International Organization For Standardization. 1991. Quality management and quality s!'setm elements - Part 2: Guidelines for services; ISO 9004-2. I a. ed., Genève.

LAGE, Beatriz H.G. 1990. Turismo e propaganda, uma análise econômica. São Paulo: USP/EC: Tese de livre-docència.

MILL, Robert C. \& MORRISON. Alastair M. 1992. The tourism system. Englewood Clifft Prentice-Hall Intemational.
NAISBITT, John. 1994. Paradoxo global. Rio de Janeiro: Campus

OMT. 1985. Tourism bill of rights and tourist code. Madrid: OMT.

OMT. 1988. Control de calidad de los productos y servicios turistico. Madrid: OMT. PURI, Subhrash C. 1994. ISO 9000 - Certificação. Rio de Janeiro: Qualitymark. ROS.NDIDR. A.C. 1989. The quest for quality in senvices, Milwaukee: Quality Press. SUE, Roger. 1988. Le loisir. 3a. ed. Paris: Presses Universitaires de France. SZWARC, Samucl. 1990. Esquecimento do cliente. O Estado de S. Paulo, 27 fev. TRENDS, Nick. 1994. Follow that star, but not to the inn. The European, 2 jun. ZETTHAMI Valarie A. PARASURAMAN A. \& BERRY, Leonard L, 1990. Delivering quality serrice - Balancing customer perceptions and expectations. New York: The Free Press. 